\title{
Construção Científica e Inovação Teórica: Um Desafio para a Epidemiologia
}

É crescente a preocupação de refletir criticamente sobre os modelos hegemônicos na epidemiologia. Habitualmente, são ressaltadas as contribuições que a disciplina trouxe ao entendimento dos problemas de saúde e doença. Algumas delas são os achados sobre a relação entre, de um lado, componentes da dieta, o fumo, a radiação nuclear, o consumo de determinados medicamentos, o uso de substâncias tóxicas na indústria, e, de outro, a incidência de doenças como câncer, doenças cardiovasculares, malformações congênitas, diabetes, etc.

No entanto, permanece uma insatisfação quanto ao alcance social dessas descobertas. Que intervenções foram geradas a partir delas e a que práticas estiveram relacionadas? Que concepções de saúde e qualidade de vida orientam a lógica do discurso produzido pela epidemiologia?

Inquietação e insatisfação denunciam, por um lado, a fragilidade e a inadequação de teorias, métodos e práticas; por outro, situam a necessidade de expandir horizontes e produzir novas práticas.

Toda teoria traz uma representação de verdade. Quanto mais ampla, mais possibilidades se desenvolvem a partir dela. Ainda assim, algo que não foi contemplado se revela de alguma maneira. São falhas, "buracos",

* Departamento de Epidemiologia. Escola Nacional de Saúde Pública — FIOCRUZ. 
que, se assimilados, possibilitam uma reorganizaçāo do conhecimento e a emergência do novo. ${ }^{1}$

No processo de lidar com a fronteira entre o conhecido e o desconhecido, de compreender o que ainda não havia sido compreendido, emergem as novidades. Este é um importante campo da reflexão epistemológica. Em diferentes concepçōes sobre o processo de construção da ciência, o novo surge como erro, fracasso, anomalia.

Kuhn, por exemplo, identificou como "anomalias" fenômenos insuspeitados que surgem periodicamente no processo da pesquisa científica orientada por um determinado paradigma. A consciência da anomalia provoca uma readaptação do conhecimento, e o que era inicialmente anômalo transforma-se em previsto. Isto se dá com dificuldade, enfrentando resistências. ${ }^{2}$

Neste processo distinguem-se ciência normal, crises e revoluçōes científicas. A ciência normal, que resiste às novidades, acaba provocando as crises e revoluçōes, as quais inauguram uma nova ciência normal. ${ }^{3}$

Já Bachelard formulou a noção de obstáculo epistemológico. O obstáculo se refere a causas de estagnação e regressāo intrínsecas ao ato de conhecer. O conhecimento se constrói através da retificação do erro, através da consciência de suas falhas históricas. A inovaçāo, a descoberta, é uma reforma radical do saber e evidencia a sua descontinuidade. ${ }^{4}$

Para Bachelard, o erro e o fracasso experimental também resultam numa mudança profunda do conhecimento. No entanto, a capacidade de lidar com a surpresa, a possibilidade de realizar outras associaçōes e articulações, se integra à investigaçāo científica. O espírito científico deveria preparar-se para receber novidades e se ampliar. "É preciso, sem cessar, tomar consciência do caráter completo do conhecimento, espreitar as oportunidades de extensão, prosseguir todas as dialéticas."

A distinção entre "ciência normal" e "revolução científica", como conceituou Kuhn, não deve ser considerada uma norma para o desenvolvimento da ciência. Mesmo não sendo uma característica intrínseca do processo de conhecimento, esta formulação é rica na constataçāo sociológica da dificuldade de ampliaçāo do espírito científico, preconizada por Bachelard.

1. MORIN E., Ciência com consciência. Portugal, Europa-América, 1982.

2. KUHN T. S., A estrutura das revoluçōes cientificas. Săo Paulo, Perspectiva, 1982, p. 90.

3. KUHN T. S., op. cit.

4. BACHELARD G., Epistemologia. Rio de Janeiro, Zahar, 1983.

5. BACHELARD G., O novo espirito científico. Rio de Janeiro, Tempo Brasileiro, 1968, p. 127. 
Se hoje vivenciamos uma "crise de paradigmas", ela é fruto da lógica que permeou o desenvolvimento científico, tecnológico e social. Lógica que foi orientada pelo crédito a verdades cuja provisoriedade constitutiva não foi considerada.

As "anomalias" que enfrentamos não se restringem a fenômenos observados em laboratórios, nem dizem respeito somente a um ou outro campo científico. Revelaram-se a partir de questões "externas" às concepções e opções da racionalidade científica moderna.

Na verdade, esta racionalidade triunfal está sub judice porque, entre outras questões, suas conquistas positivas foram contrapostas a possibilidades terríveis de aniquilamento.

Perpetuam-se as desigualdades que mantêm na miséria a maior parte da população. Apesar dos recursos tecnológicos, a fome, a mortalidade infantil, as epidemias por doenças transmissíveis fazem parte do cenário mundial. Mas, além disso, surgiram as questões que confrontam a condição humana e, assim, colocam em xeque a própria sobrevivência da espécie.

Destacam-se entre estas, como possibilidade, o uso da energia nuclear para destruição em massa e a relação predatória da espécie humana com a Terra. Enfim, estão presentes conseqüências regressivas em termos ambientais, territoriais, sanitários e culturais jamais vivenciadas pela história humana. Percebe-se nestes questionamentos a intenção de refazer o próprio sentido da ciência.

Este é sem dúvida um dos aspectos que estimulam um maior interesse na discussão conceitual da epidemiologia. Influência de uma preocupação mais ampla com a humanização da ciência e com a reflexão sobre seu alcance social.

Outra possibilidade é de que este interesse na discussão teórica esteja inspirado na necessidade de conquistar maior legitimidade frente a outros campos científicos correlatos, buscando-se garantias de maior cientificidade para um campo cuja autonomia ainda é frágil.

Pensar criticamente alternativas para a construção do conhecimento em epidemiologia pressuporia aprofundar o entendimento da lógica e de representações que se moldaram historicamente no núcleo hegemônico da disciplina. Que aspectos do desenvolvimento teórico atual possibilitariam romper com os modelos fechados? Quais alternativas teóricas para a disciplina incorporam as interrogações direcionadas ao núcleo epistemológico da ciência positiva?

A epidemiologia surge no século XIX através de vários trabalhos considerados precursores da sua institucionalização como disciplina cien- 
tífica. Esta racionalidade é gerada a partir do desenvolvimento de outros campos de conhecimento.

Certas opções que caracterizam a ciência moderna vão orientar também a racionalidade epidemiológica: a ciência como possibilidade de dominação da natureza; a verdade associada à utilidade; a perspectiva de apreensão objetiva dos fatos; a separação entre ciência e filosofia; a ciência considerada como forma superior de conhecimento, etc.

O desenvolvimento da epidemiologia implicará a utilização da matemática como instrumento de quantificação e ordenamento da observação da realidade. Mas somente após o surgimento da medicina científica, no século XVIII, amadurecem as condições para o surgimento da epidemiologia. Como afirmou Gonçalves, “a epidemiologia só pode, lógica e historicamente, suceder ao nascimento da clínica". ${ }^{6}$

A compreensão do conceito de doença a partir da afirmação do método anatomoclínico, da integração da observação e dissecação do corpo morto para o entendimento do funcionamento do corpo vivo, foi a condição histórica da medicina científica. ${ }^{7}$ Tal opção epistemológica orientou a racionalidade epidemiológica.

Entretanto, é necessário afirmar que a epidemiologia nasceu no contexto de predominância da teoria miasmática, que concebia a origem das doenças a partir de emanações e eflúvios, idéia posteriormente considerada superada e arcaica. Porém, por estar relacionada à qualidade do ar e do ambiente, esta teoria permitiu uma articulação mais ampla do pensamento sanitário.

Ancorados na teoria dos miasmas, diversos trabalhos de medicina social relacionaram, na época, situação sanitária e vida social, modo de vida e trabalho. Cabe destacar que esta produção foi também marcada pelos movimentos sociais da época e pelo surgimento das ciências sociais. Exemplos importantes são os trabalhos de Villermé, na França, e Virchow, na Alemanha. ${ }^{8}$ A lógica da medicina social foi, porém, subordinada. Tanto pela racionalidade naturalizante da ciência moderna, como pelos interesses econômicos e políticos dominantes.

Com a teoria do contágio, portanto, a epidemiologia funda a sua especificidade, caudatária da razão científica positiva. Ocorreu, indubita-

6. GONÇALVES R. B. M., "Reflexão sobre a articulação entre a investigaçāo epidemiológica e a prática médica a propósito das doenças crônica-degenerativas."In: Epidemiologia Teoria eObjeto, D.C. Costa (org.). São Paulo, Hucitec-Abrasco, 1990, p. 66.

7. FOUCAULT M., O nascimento da clínica. Rio de Janeiro, Forense Universitária, 1977.

8. BARRETO M. L. A, "Epidemiologia, sua história e crises: notas para pensar o futuro." In: Epidemiologia Teoria e Objeto, D.C. Costa (org.), op. cit. 
velmente, um estreitamento do pensamento sanitário, que a partir de então se dirigiu à busca de causas "verdadeiras e específicas", deixando para trás a reflexão sobre os diferentes aspectos que intervêm na origem e no desenvolvimento dos problemas de saúde e doença. ${ }^{9}$

Nesse sentido, a obra de $S_{n o w}{ }^{10}$ é exemplar. Num raciocínio extremamente amplo, ele articulou inúmeras conexões a respeito de seu problema e, ao mesmo tempo, antecipou a redução epistemológica que a revolução pasteuriana mais tarde provocou.

Sem dúvida, esta redução influenciou a institucionalização da epidemiologia como disciplina científica. A compreensão de que, para o novo campo, o critério maior de cientificidade seria o das ciências da natureza tendeu a radicalizar esta tendência.

Segundo Bourdieu, um campo científico se movimenta em torno da luta pela autoridade científica. Esta legitimidade se define, inseparavelmente, como capacidade técnica e poder social. Competência científica, portanto, significa poder falar e agir legitimamente. ${ }^{11}$ Tais características também marcariam o discurso científico produzido pela epidemiologia no seu processo de institucionalização.

Os primeiros departamentos de epidemiologia surgiram nos EUA e Inglaterra na década de $1920 .{ }^{12}$ A construção do método epidemiológico, herdando da racionalidade positiva a concepção de rigor, utilizou a formulação já trabalhada pela sociologia e a psicologia funcionalistas, que buscavam trazer para as ciências sociais os mesmos rigor e objetividade das ciências físicas. Isto se deu a partir da elaboração de desenhos de estudo, escalas, questionários com a preocupação de evitar os diversos tipos de bias, erros de medida e variáveis de confusão, garantindo validade e confiabilidade aos desenhos e medidas. ${ }^{13}$

O campo científico da epidemiologia cimentou-se em torno do método. O método entendido como instrumento, desenho de investigação, e não como processo de elaboração e explicitação de teorias.

Desde a publicação do primeiro manual, em 1960, até hoje, houve grande desenvolvimento e sofisticação das técnicas e dos desenhos. ${ }^{14}$ No

9. AYRES J. R. C. M., “A epidemiologia e o projeto emancipador nas práticas de saúde: A crítica da razāo instrumental na constituição histórica da ciência epidemiológica". Tese de Mestrado, Universidade de São Paulo/USP, 1991.

10. SNOW J., Sobre a maneira de transmissão do cólera. Sāo Paulo, Hucitec, 1990.

11. BOURDIEU P., "O campo científico". In Pierre Bourdieu, Coleçāo Grandes Cientistas Sociais, São Paulo, Ática, 1983, p. 122-155

12. BARRETO M.L., op. cit.

13. SUSSER M., "Epidemiology in the United States After World War II: the Evolution of Technique." Epidemiol. Rev., 1985, 17:147-177. 
entanto, os estudos mantiveram, nos aspectos fundamentais, a mesma lógica empirista e indutivista. ${ }^{15}$

Esta função de normalização metodológica ressalta a influência da dimensão sociológica no processo de institucionalização do campo. A lógica de territorialização disciplinar, de demarcação do espaço de autoridade, poder e competência frente a outros campos que interrogam o mesmo objeto: saúde e doença em populaçōes humanas.

Mas a opção preferencial pela empiria foi criticada no interior da disciplina. Susser apontou a importância de que o investigador explicite o "sistema de referência" que o orienta no processo de investigação. Para ele, "os conceitos e o sistema de referência determinam as causas que procuramos". ${ }^{16}$

No entanto, foi principalmente a partir da introdução do pensamento popperiano que a epidemiologia começou a buscar maior flexibilidade, percebendo as frágeis bases do indutivismo frente a concepçóes mais elaboradas da teoria da ciência. Isto porque, para Popper, a formulação de teorias precede a observação: "A observação é sempre seletiva: (...) para descrevê-la é preciso empregar uma linguagem apropriada, implicando similaridade e classificação, que, por sua vez, implicam interesses, pontos de vista e problemas." 17

A ciência originar-se-ia de problemas, cabendo aos cientistas resolvêlos mediante a elaboração de uma teoria. As teorias (conjecturas) seriam criaçōes livres, influenciadas pela imaginação, as paixões, os pontos de vista. Mas, para ser demarcada como científica, a teoria deveria ser refutável. Deveria ter alto conteúdo empírico. ${ }^{18}$

Em relação ao empirismo, a constataçāo de que as teorias científicas contêm elementos que não se restringem à ciência não modificou a concepção popperiana de objetividade em nenhum aspecto fundamental. As teorias científicas assegurariam objetividade e progresso em direçāo à verdade quando submetidas a tentativas de refutação lógica e empírica e ao serem confrontadas criticamente com outras teorias.

Popper reconheceu que "a história da ciência, como a história de todas as idéias humanas, é feita de sonhos irresponsáveis, de erros e de obstinação. Mas a ciência é uma das poucas atividades humanas - e talvez a

14. BARRETO M. I., "A epidemiologia, sua história e crises: notas para pensar o futuro," op. cit.

15. ALMEIDA FILHO N.. Epidemiologia sem números. Uma introduçâo crítica à ciência epidemiológica. Rio de Janeiro, Editora Campus, 1989.

16. SUSSER M., Causal Thinking in the Health Science. Nova York, Oxford University Press, 1973.

17. POPPER K.R., Conjecturas e refutações. Universidade de Brasília, 1982, p. 223.

18. POPPER K.R., op. cit. 
única - em que os erros são criticados sistematicamente (e, com freqüência, corrigidos). Por isso podemos dizer que, no campo da ciência, aprendemos muitas vezes com nossos erros; por isso podemos falar com clareza e sensatez sobre o progresso científico. Na maior parte dos outros campos de atividade, ocorrem mudanças, mas raramente há progresso científico - a não ser dentro de uma perspectiva muito estreita dos nossos objetivos neste mundo. Quase todos os ganhos são neutralizados por alguma perda - e quase nunca sabemos avaliar as mudanças." ${ }^{19}$

A correção progressiva de erros permitiria uma aproximação crescente à verdade objetiva. Este rumo em direção à verdade tornaria a tradição científica capaz de formular enunciados universais, mesmo que provisórios.

O processo de demarcação e legitimação de teorias científicas, através da refutação, possibilitaria a disjunção entre sujeito e objeto, ainda confundidos na etapa de elaboração de conjecturas.

Popper considerou que a observação seria feita a partir de pontos de vista diferentes e de instrumentos que seriam históricos. Mas não admitiu que o consenso criado pela tradição crítica através do confronto entre teorias conflitantes permaneceria histórico e contingente. Historicidade e presença de condicionantes, que marcariam o elo entre ciência e interesse, foram percebidos como irredutíveis por vários outros autores, como $\mathrm{Ha}$ bermas ${ }^{20}$ e Morin..$^{21}$

Pensar que a ciência não estaria imune a perdas, como qualquer outra atividade humana, e que a noção de continuidade e progresso deva ser relativizada provocaria um deslocamento ético na produção de verdades científicas.

Os cientistas seriam responsáveis e assumiriam riscos na escolha e delimitação de seus problemas. Estariam constantemente pensando sobre a pertinência de suas questões - as consequências sociais, ambientais e éticas das suas opções. Nesse sentido, a produção de conhecimento poderia tomar o caminho dialógico com a perspectiva emancipatória, qualificando o lugar do fazer científico a partir da reflexão.

Este debate, travado no plano da teoria do conhecimento, teria implicações para o desenvolvimento teórico e desdobramentos práticos da epidemiologia? A discussão atual em torno da introdução da filosofia de Popper

19. POPPER K.R., op. cit.

20. HABERMAS J., Conhecimento e interesse. Rio de Janeiro, Guanabara, 1987.

21. MORIN E., op. cit. 
na epidemiologia necessitaria registrar um elemento fundamental: o seu conceito de verdade. ${ }^{22}$

A incorporação de Popper se deteve em afirmar a lógica da refutação versus verificação; da dedução versus indução; e da elaboração de teorias precedendo a observação (ver, por exemplo, Buck; ${ }^{23}$ Maclure; ${ }^{24}$ e Weed, ${ }^{25}$ versus Susser; ${ }^{26}$ Pearce \& Crawford; ${ }^{27} \mathrm{Ng}$ Stephen ${ }^{28}$ ).

A introdução da filosofia de Popper na epidemiologia traria contribuições, no entanto, para uma modernização do método.

Talvez seja possível detectar convergências em alguns aspectos entre o pensamento popperiano e a contribuição de Miettinem, um dos mais radicais críticos dos paradigmas e dogmas tradicionais da epidemiologia.

Para ela, "as tradições metodológicas da epidemiologia, além de terem dado origem a um malformado 'campo de estudo', são absolutamente inadequadas para o propósito da pesquisa etiológica". ${ }^{29}$

Com efeito, a crença de que uma explicação epidemiológica pode surgir simplesmente de observações, e não a partir de um confronto com conceitos e teorias, levou a epidemiologia a realizar estudos monumentais, com resultados pouco significativos frente ao dispêndio enorme de recursos.

A introdução do pensamento popperiano na epidemiologia poderia trazer maior racionalidade à execução dos desenhos de estudo. Num certo sentido, romper-se-ia com a formalidade empirista e buscar-se-iam estudos mais enxutos, que definiriam e selecionariam os participantes em função de objetivos precisos, otimizando a possibilidade de trabalhar com uma teoria previamente formulada.

Uma repercussão possível deste pensamento poderia ser identificada na revalorização dos estudos de caso e controle (muito mais rápidos e baratos) em relação aos estudos de coorte (demorados e caros). Constatou-se que as diferenças de rigor entre um e outro são uma formalidade empirista.

22. AYRES J.R.C.M., "O problema do conhecimento verdadeiro em epidemiologia." Revista de Saúde Pública 26(3), 1992

23. BUCK C., "Popper's Philosophy for Epidemiologists." Int. J. Epidemiol., 1975, 4:159-168

24. MacLURE M., "Popperian Refutation in Epidemiology." Am. J. Epidemiol., 1985, 121:343-350.

25. WEED D., "On the Logic of Causal Inference." Am. J. Epidemiol., 1986, 123:965-979.

26. SUSSER M., "The logic of Sir Karl Popper and the practice of epidemiology." Am. J. Epidemiol., 1986, 124:711-718.

27. PEARCE N. \& CRAWFORD-BROWN D., "Critical Discussion in Epidemiology: Problems with the Popperian Approach." J. Clin. Epidemiol., 1989, 42:177-184.

28. NG STEPHEN K. C., "Does Epidemiology need a new Philosophy?" Am. J. Epidemiol., 1991, 133:1073-1077.

29. MIETTINEN O., "The Clinical Trial as a Paradigm for Epidemiologic Research," J. Clin. Epidemiol. 42:491-6,1989. 
Porém, quaisquer que venham a ser as repercussões da leitura de Popper na epidemiologia, elas sugerem uma tentativa de alcançar maior racionalidade, sem alterar a lógica e as características fundamentais do método epidemiológico.

Por exemplo, um aspecto importante que este desenvolvimento não questiona - pelo contrário, radicaliza - é uma perspectiva naturalizante e universalizante do estudo epidemiológico. Ao se afastarem do empirismo convencional, os desenhos de investigação tenderiam a utilizar abstrações conceituais que poderiam provocar uma maior descontextualização em relação à temporalidade, espacialização e características dos sujeitos.

Esta é uma das principais críticas formuladas ao conceito epidemiológico de risco. Como observou Almeida Filho, o conceito de risco, no seu componente preditivo, quebra os limites do tempo e do espaço. Isto retiraria a historicidade do conceito, dotando-o de uma dimensão generalizante que denuncia um entendimento empobrecido a respeito do social. ${ }^{30}$

O conceito de risco não contemplaria as diferenças, a singularidade, dos processos concretos de saúde e doença. O risco, no discurso epidemiológico, situar-se-ia fora do sujeito. Seria uma propriedade das populações. A sua referência seria coletiva. No entanto, a perspectiva individualizante das práticas de saúde tenderia a torná-lo preferencialmente um conceito auxiliar na clínica. Esta incorporação do risco pelo discurso clínico provocaria um processo de desumanizaçāo e dessubjetivaçāo de sua prática. ${ }^{31}$

Este desenvolvimento conceitual produz práticas sociais com orientaçóes éticas muito distantes da pretensa neutralidade do discurso que fala em nome da "verdade científica". Isto resgata a questão inicial deste texto. Até que ponto a discussāo teórica na epidemiologia está referida a uma busca de legitimação da autoridade e competência, de acordo com os critérios da racionalidade científica dominante? Ou se preocupa com a orientação ética, o alcance social e a explicitação mais ampla dos valores humanós envolvidos no saber construído?

De certo modo, a crítica ao modelo naturalista e universalizante da medicina, que substancia também a racionalidade epidemiológica hegemônica, marcou o surgimento do pensamento crítico em saúde coletiva, como apontou Birman. Tornou-se necessário considerar a dimensão de valor e as relações de força presentes na vida social. Compreender que as "relaçōes do sujeito com o seu corpo, com os outros, com as instituições

30. ALMEIDA FILHO N. A., "Desconstruçāo do conceito de risco." In: Avanços conceituais em epidemiologia: desafios para a década de 90. Rio de Janeiro, ENSP, 1992.

31. ALMEIDA FILHO N., op. cit.. 
e com as práticas sociais são mediadas pela linguagem, pelos códigos culturais estabelecidos numa tradiçāo histórica e lingüística" permitiria orientar a construção do conhecimento em outras bases epistemológicas. ${ }^{32}$

Sem dúvida, o pensamento popperiano não contemplou estas questões fundamentais. Ele possibilitou alguns avanços em relação ao empiricismo, mantendo, porém, a tradiçâo epistemológica da ciência positiva.

\section{Conclusão}

Que alternativas metodológicas se apresentaram diante dessas inúmeras questōes?

Almeida Filho apontou a necessidade de a epidemiologia expandir suas estratégias de pesquisa, tanto no sentido da profundidade quanto no da extensividade. Colocou a perspectiva de uma maior integração com estratégias das ciências sociais, especialmente com os métodos qualitativos de análise da antropologia. ${ }^{33}$ Esta opção, certamente, nāo se restringiria à dimensāo metodológica. Ela redefiniria o objeto epidemiológico, qualificando-o também como um objeto das ciências sociais.

Uma preocupação a ser desenvolvida nesse âmbito é, por exemplo, a concepção de erro e validade dos estudos epidemiológicos, que inferem o risco a partir de informaçōes dos indivíduos. Estas informações são colhidas segundo regras de rigor e precisão que pressupõem o máximo de neutralidade. Para isso, são utilizados estudos cegos, questionários e instrumentos de medida padronizados e técnicas que buscam evitar o viés decorrente da relação entrevistado-entrevistador. Nesse sentido, deixa-se de reconhecer o caráter simbólico do sujeito, de seu corpo e do coletivo que ele participa.

Considerar a intersubjetividade da relação entrevistado-entrevistador e não tentar neutralizá-la talvez seja uma opção metodológica a ser introduzida. Esta é uma abordagem que já é desenvolvida nas ciências sociais (ver Minayo $\left.{ }^{34}\right)$.

Integrar métodos implica, antes de tudo, integrar a teoria. Só a partir de uma mesma base teórica, de uma definição clara do objeto de estudo, poderemos ter condições de escolher qual a estratégia de pesquisa mais adequada para a apreensāo do nosso objeto.

32. BIRMAN J., "A physis da saúde coletiva." Physis, 1991, 1:7-11.

33. ALMEIDA FILHO N., op. cit.

34. MINAYO M. C. de S., O desafio do conhecimento. Metodologia de pesquisa qualitativa em saúde. São Paulo, Hucitec, 1989. 
Esta integração esbarra, entre outros problemas, na questão da competência. Como um só investigador pode dar conta de tamanha abrangência? O trabalho coletivo interdisciplinar, por sua vez, esbarra nos diferentes pontos de vista, interesses e relações de poder.

Uma outra alternativa, apontada por Breilh ${ }^{35}$ e Almeida Filho, ${ }^{36}$ propōe a utilização de modelos matemáticos dinâmicos na análise de estudos epidemiológicos. Esta sugestão permitiria superar a linearização que os modelos de regressão logística impõem por utilizarem o espaço cartesiano, propondo-se para isso funçōes nāo lineares, através do emprego de espaços dinâmicos, como, por exemplo, o fractal.

Para utilizar este novo enfoque na epidemiologia, numa perspectiva integrada, esbarramos de novo na questão da competência. Não bastaria apenas conhecer profundamente matemática para dar conta desse desafio. Desafio que seria fundamental para poder operacionalizar empiricamente abordagens teóricas de objetos totalizados, dinâmicos, e processuais.

Pensar a eficácia explicativa de um campo refere-se, sem dúvida, à sua capacidade de resolver problemas. Torna-se necessário formular novas técnicas e métodos, redimensionar os já construídos. Mas só isso não basta. A reflexão filosófica é fundamental. Os problemas vão encontrando novas significaçōes constantemente, e só a introdução da reflexão no cotidiano da prática científica e a elaboraçāo do sentido da mesma permitiriam soluções com alternativas integrativas.

Por ora, a superação da crise atual exige, no mínimo, pensar a organização da produçāo do conhecimento em bases mais cooperativas. Alcançar esse objetivo pode não ser simples. A organização da ciência e a demarcação dos campos científicos, como vimos, constituem também relaçōes de poder. O universo "puro" da mais "pura" ciência é um campo social como outro qualquer. O campo científico define-se, indissociadamente, como capacidade técnica (possibilidade) e como poder (dominação). ${ }^{37}$

Sem colocar em um novo patamar a interlocução e a capacidade de lidar com os conflitos, interesses e contradiçōes inerentes a qualquer prática humana será muito difícil criar uma base para qualquer compreensão. Elaborar novas regras para a produção científica é uma tarefa talvez incontornável.

35. BREILH J., "A reproduçāo social e a investigação em saúde coletiva. Construção do pensamento e debate." In: Epidemiologia Teoria e Objeto, D.C. Costa (org.), op. cit.

36. ALMEIDA FILHO N., "Paradigmas em Epidemiologia." I Congresso Brasileiro de Epidemiologia. Anais, Rio de Janeiro, Abrasco, 1990.

37. BOURDIEU P., "O Campo Científico." In: Pierre Bourdieu, Coleçäo Grandes Cientistas Sociais, op. cit. 
Como reflexão final, cabe chamar atenção para o fato de que ainda hoje a polaridade criada entre teoria dos miasmas versus teoria do contágio permanece como questão não solucionada epistemologicamente no interior do campo.

Há na discussão sobre a teoria do contágio uma questão que confunde: uma tendência a colocar no mesmo plano a positividade que este saber possibilitou na intervenção em determinadas doenças e a redução decorrente de sua assunção como explicação maior a respeito da doença e, indiretamente, da saúde.

A radicalização da teoria do contágio, sem a preocupação em resgatar as verdades que a teoria miasmática propôs, foi, sem dúvida, conseqüência de uma necessidade instrumental. Se a teoria miasmática tornou-se arcaica após a descoberta de agentes específicos, a teoria dos germes, em várias outras dimensões, também falharia na sua possibilidade explicativa.

A orientação epistemológica que construiu os instrumentos e saberes que desaguaram na teoria do contágio já tinha sido gestada a partir do desenvolvimento da ciência moderna e do nascimento da clínica. Esta orientação produziu um saber de espetacular positividade na instrumentação das práticas de saúde. Retomar o esquecido e buscar novas alternativas dificilmente poderão ser feitos sem os instrumentos da bacteriologia e da biologia molecular.

Foucault percebeu como é forte e paradoxal a relação de possibilidades e limites gestadas pelo positivismo. "Nos últimos anos do século XIX, a cultura européia construiu uma estrutura que ainda não foi desatada; começamos apenas a desembaraçar alguns de seus fios, que nos são ainda tão desconhecidos que os tomamos de bom grado como maravilhosamente novos ou absolutamente arcaicos, enquanto há dois séculos constituíram a trama sombria, mas sólida, de nossa experiência." 38

Como desatar esses fios que teceram nossas representações de mundo? Como nos libertar dos seus muros, redimensionando as possibilidades? Construir o novo certamente pressupõe elaborar a experiência com o velho. Este é o desafio que nos provoca.

38. FOUCAULT M., O nascimento da clínica, op. cit. 


\section{RESUMO}

\section{Construção científica e inovação teórica: um desafio para a epidemiologia}

Tem sido crescente a reflexão sobre a construção do conhecimento em epidemiologia. Até que ponto este interesse teórico está referido a uma preocupação mais ampla com a humanização da ciência? Ou se restringe à busca de legitimação da autoridade e da competência científica, de acordo com a racionalidade dominante?

Este trabalho analisa o desenvolvimento da epidemiologia, a sua institucionalização como disciplina científica e a concepção hegemônica de método construída nesse processo. Analisa também a introdução do pensamento popperiano, que se apresentou como crítico no debate interno da epidemiologia norte-americana.

Finalmente, refere-se a alternativas metodológicas apontadas por alguns autores frente a questões e impasses identificados no desenvolvimento da disciplina.

\section{ABSTRACT \\ Scientific construction and theoretical innovation: a challenge for epidemiology}

The reflection upon the construction of knowledge in epidemiology is increasing. To what extent this theoretical interest refers to a broader preocupation with the humanization of science? Or is it restricted to the search of legitimation of authority and scientific competence, according to the dominating rationality?

This work analyses the development of epidemiology, its institutionalization as scientific discipline and the method's hegemonic conception built within this process. It also analyses the introduction of the Popperian thought, who was a critic in the internal debate of the american epidemio$\log$.

Finally, it refers to methodological alternatives mentioned by some authors in face or questions and impasses identified in the development of the discipline. 


\section{RESUME}

Construction scientifique et inovation théorique: un défi pour l'épidémiologie

Ce texte a comme but analyser le développement de l'épidémiologie, son processus d'institutionalisation et la conception méthodologique qui a été établie comme hégémonique dans ce processus. L'article discute les alternatives méthodologiques qui ont étè posées par plusieurs auteurs face aux questions, problèmes et impasses produits dans le processus de développement de l'épidémiologie. 